\title{
LAS ACUÑACIONES ROMANAS DE SEXTO POMPEYO EN HISPANIA
}

\author{
POR \\ LUIS AMELA VALVERDE \\ Asociación Española de Numismática (A.N.E.)
}

PALABRAS CLAVE: Acuñaciones provinciales en Hispania. Guerras pompeyanas. Iconografía. Tipología. Metrología. Gens Pompeia. 45-44 a.C.

KEY WORDS: Provincial coinage in Hispania. $2^{\text {nd }}$ Civil War. Iconography. Tipology. Weigths. Gens Pompeia. 4544 BC.

\section{RESUMEN}

En este artículo se describen las monedas emitidas por Sexto Pompeyo en Hispania durante los años 45-44 a.C. (una emisión de denarios y dos de ases, RRC 477-479), así como las causas que las originaron: pago de las tropas que luchaban contra César así como reivindicar la memoria de su familia. Se analizan los diferentes tipos iconográficos de anversos y reversos, leyendas y lugar de emisión.

\section{SUMMARY}

This article describes the coins minted by Sextus Pompey in Hispania from 45 to $44 \mathrm{BC}$ (one issue of denarii and two of asses, RRC 477-479) and their causes: payment for troops fighting against Caesar and the recovery of the memory of his family. The different obverse and reverse iconographical types, legends and place of issue are discussed.

La moneda era utilizada esencialmente en las guerras como medio de pago a las tropas de los diversos bandos en lucha pero, a la vez, servía como medio de propaganda política (Beltrán Martínez 1987, 56-57) mediante las inscripciones y/o símbolos grabados en ellas. Evidentemente, la moneda vehicula un mensaje que figura y significa, por lo que no es de extrañar que los responsables de una emisión monetaria la utilicen con fines propagandísticos para influir en sus conciudadanos y en la opinión pública, fuese o no romana.

En la historia de las guerras civiles romanas son conocidas las acuñaciones provinciales que emitieron los diferentes bandos, en especial las hispanas efectuadas durante el conflicto entre cesarianos y pompeyanos. Tanto unos como otros usaron este medio propagandístico, aunque si bien Pompeyo Magno debía aparecer como señor del mundo romano, sus partidarios no utilizaron los mismos procedimientos que los cesarianos, para no ir en contra de las tradiciones republicanas que decían defender, pero en su desarrollo no fueron tan hábiles como sus enemigos (Pérez 1989, 33-39).
Las monedas romanas acuñadas por la gens Pompeia en Hispania cumplen con las líneas generales trazadas por Alföldi para las acuñaciones del periodo: en el siglo i a.C. se puede observar cómo, en los tipos monetales, los antepasados de las grandes familias son desplazados por sus descendientes vivos, a la vez que se procede a relatar acontecimientos contemporáneos (Alföldi 1956, 66) ${ }^{1}$. En estas piezas se puede apreciar la manifestación del poder político-militar (representación de armas, barcos, etc.) que disfrutaron los pompeyanos en la Península Ibérica, a la vez que la gloria que alcanzaron (cifrado en la palabra imperator utilizada por los hijos de Pompeyo Magno; Amela 1990-1991, 196) ${ }^{2}$.

Las emisiones pompeyanas fueron acuñadas en momentos diferentes, que corresponden a los periodos en que se ha de dividir la guerra entre Pompeyo Magno y sus hijos y César en Hispania ${ }^{3}$. Más importante, reflejan la disposición de esta familia con respecto a la Península Ibérica. Así, las acuñaciones de Pompeyo Magno (RRC 446-447) muestran la estrategia que pensaba seguir en el enfrentamiento contra César, mostrando la flota de Oriente y las legiones de Occidente. Las de Cneo Pompeyo hijo representan la acogida - y ayuda - que recibió de las provincias hispanas (RRC 469-471), convirtiéndose la Península Ibérica en el único territorio que resistió al invencible César. En cambio, las acuñaciones de Sexto Pompeyo son más reservadas (RRC 477-479), debido a las muertes de su padre y de su hermano mayor, a quienes recuerda (Amela 1990-1991, 192).

\footnotetext{
' De esta forma, las insignias o monogramas de las gentes gobernantes van substituyendo a los signos y símbolos de la soberanía del Estado, fase que se acentúa tras L. Cornelio Sila con la mención de varios generales con poderes extraordinarios al lado del responsable de la acuñación. En su última fase, a finales de la República, la sola mención de los imperatores muestra cómo el alto poder ejecutivo usurpa los órganos de la administración en una clara progresión hacia la monarquía.

${ }^{2}$ En ninguna de ellas se menciona el nomen Pompeius, sino que su identificación estriba en la mención del cognomen en el caso de las amonedaciones de Pompeyo Magno, mientras que en las de sus dos hijos aparece el praenomen junto con el cognomen (Millán 1965, 295-296. Battenberg $1980,99)$.

3 Gil Farrés $(1966,233)$ manifiesta que esta periodización se puede extender a todo el Mediterráneo Occidental.
} 
Estas acuñaciones constituyen por sí solas importantísimos documentos sobre el desarrollo de la segunda guerra civil en la Península Ibérica, que muchas veces no ha sido suficientemente valorado por la investigación actual. Gracias a ellas puede apreciarse las buenas relaciones existentes entre la gens Pompeia e Hispania (a la que se puede considerar una segunda patria; Millán 1965, 298), ya que sustentó la bandera pompeyana en tres ocasiones. Buena muestra de ello es la numerosa clientela pompeyana existente, bien documentada por las fuentes literarias (BAfr. 22, 4. Caes. BCiv. 2, 18, 7. Sall. Cat. 19, 5) ${ }^{4}$.

En el presente estudio se analiza las acuñaciones romanas RRC 477, 478 y 479 (una emisión de denarios y dos de ases), realizadas en Hispania por Sexto Pompeyo durante los años 45-44 a.C. ${ }^{5}$. Sus descripciones son las siguientes:

1) RRC $477^{6}$. SEX. MAGNUS PIUS IMP., denario del año 45-44 a.C.

- RRC 477/1a. Anv.: cabeza de Cneo Pompeyo Magno a dra., antes SEX MAGNVS hacia arriba, detrás IMP hacia abajo, debajo $B$; línea de puntos. Rev.: la Piedad de pie a izq., llevando una rama de palma en la mano dra. y un cetro en la mano izq., detrás PIETAS hacia arriba; línea de puntos.

- RRC 477/1b. Anv.: igual, pero antes SEX MAGN hacia arriba, detrás IMP hacia abajo, debajo SAL; línea de puntos. Rev.: igual.

- RRC 477/2. Anv.: cabeza de Cneo Pompeyo hijo a izq., antes SEX MAGNVS hacia abajo, detrás IMP hacia arriba, debajo SAL; línea de puntos. Rev.: igual.

- RRC 477/3a. Anv.: igual a la 1a; alrededor SEX MAGN PIVS IMP, debajo SAL. Rev.: igual.

- RRC 477/3b. Anv.: igual a la anterior, pero sin SAL. Rev.: igual.

${ }^{4}$ Cfr. Amela Valverde, L.: «El desarrollo de la clientela pompeyana en Hispania», SHHA, 7, 1989, 105-117; «La clientela de Cneo Pompeyo Magno en Hispania», Historia y Vida, 270, 1990, 90-97; La clientela de Cneo Pompeyo en Hispania, Diss. Barcelona, 2000.

${ }_{5}$ Hay que destacar que la emisión bilingüe de Kelse se ha atribuido a Sexto Pompeyo. Igualmente, a este momento histórico hay que atribuir una emisión de Toleto y quizás la de Clounioq. Cfr.: Villaronga (1967, 133-142) y Amela (1998, 17-23). Collantes Pérez-Ardá (1987-1989, 62, 80, 90 y 9293) considera que, por características metrológicas, diversas cecas hispánicas (Saguntum, Castulo, Secobris, etc.) amonedarían para la causa de los hijos de Pompeyo Magno, pero esto debe analizarse más detalladamente. Sobre los sistemas metrológicos utilizados en Hispania, cfr.: Villaronga, L., «Metrologia de les monedes antigues de la península Ibérica», ANum, 28, 1998, 53-74.

${ }^{6}$ Crawford (RRC, p. 486) señala la existencia de 6 cuños de anverso (1 recortado) y 9 cuños de reverso.
2) RRC $478^{7}$. MAGNUS PIUS IMP. y EPPIUS LEG., as del año 45-44 a.C.

- RRC 478/1a. Anv.: cabeza laureada de Jano; en el centro un altar ${ }^{8}$; encima MAGNVS, MAGNVS, MAGNV o MAGN; debajo PIVS IMP F. Rev.: proa de barco a dra., encima EPPIVS, debajo LEG.

- RRC 478/1b. Anv.: igual, pero sin altar o leyenda, encima I. Rev.: igual.

3) RRC $479^{9}$. MAGNUS PIUS IMP., as de los años 45 a.C. en adelante.

- RRC 479/1. Anv.: cabeza laureada de Jano, con rasgos de Cneo Pompeyo Magno, encima MAGNVS, MAGNV, MAGN o MGN. Rev.: proa de nave a dra., encima PIVS, debajo IMP.

La fecha de emisión de estas monedas se sitúa entre la batalla de Munda y la salida de Sexto Pompeyo de Hispania, años 45-44 a.C., pero sin poder puntualizarse más, a pesar de que se han hecho varios intentos, todos ellos sin resultado positivo ${ }^{10}$.

Sobre la atribución de estas piezas a talleres peninsulares, hay algunos puntos que aclarar en cuanto a las monedas de bronce. En cuanto al as RRC 478, varios investigadores (Grueber 1910, 372-373. Sydenhaim 1952, 174. Millán 1965, 299. RRC, p. 487) lo consideran hispano, e incluso Crawford utiliza para su descripción un ejemplar hallado en la Península. Villaronga señala que no se habría acuñado en Hispania, ya que no ha visto esta pieza «ni en museos ni en colecciones de España» ni en los mercados de anticuarios de Madrid y Barcelona (Vi-

7 RPC (p. 146; Suppl., p. 12) le dan primero un módulo de $28-31 \mathrm{~mm}$, con un peso medio de $17,18 \mathrm{gr}$ (41 ejemplares); luego un peso medio de 17.03 gr (62 ejemplares), con un total de 18 cuños de anverso en 87 piezas estudiadas.

${ }^{8}$ Grueber $(1910,372)$ señala que es inusual la representación de un altar entre las cabezas de Jano, que únicamente se había dado en un as de L. Rubrius Dossenus, del año 87 a.C. (RRC 348/5).

9 RPC (p. 180; Suppl., p. 12) le dan primero un módulo de $28-32 \mathrm{~mm}$, con un peso medio de $21,11 \mathrm{gr}$ (185 ejemplares); luego un peso medio de 21.63 gr (581 ejemplares), con un total de 193 cuños de anverso en 819 piezas estudiadas.

${ }^{10}$ Ferreiro $(1993,413)$ señala que Sexto Pompeyo debió de desplazarse a la Ulterior (en donde su actividad fue mayor y de más importancia) en otoño del año 45 a.C., por lo que si se considera que éste salió de Hispania (en virtud del pacto alcanzado con M. Emilio Lépido) a finales del verano del año 44 a.C., es forzoso considerar que si estas monedas se acuñaron en esta provincia debió ser en este periodo de tiempo. Grant $(1969,23)$ y Crawford (RRC, p. 94) opinan que comenzarían a emitirse a finales del año 45 a.C. Finalmente Sear $(1998,137)$ afirma que la brevedad de las series de plata de Sexto Pompeyo abonaría que se acuñasen incluso después del asesinato de César. 


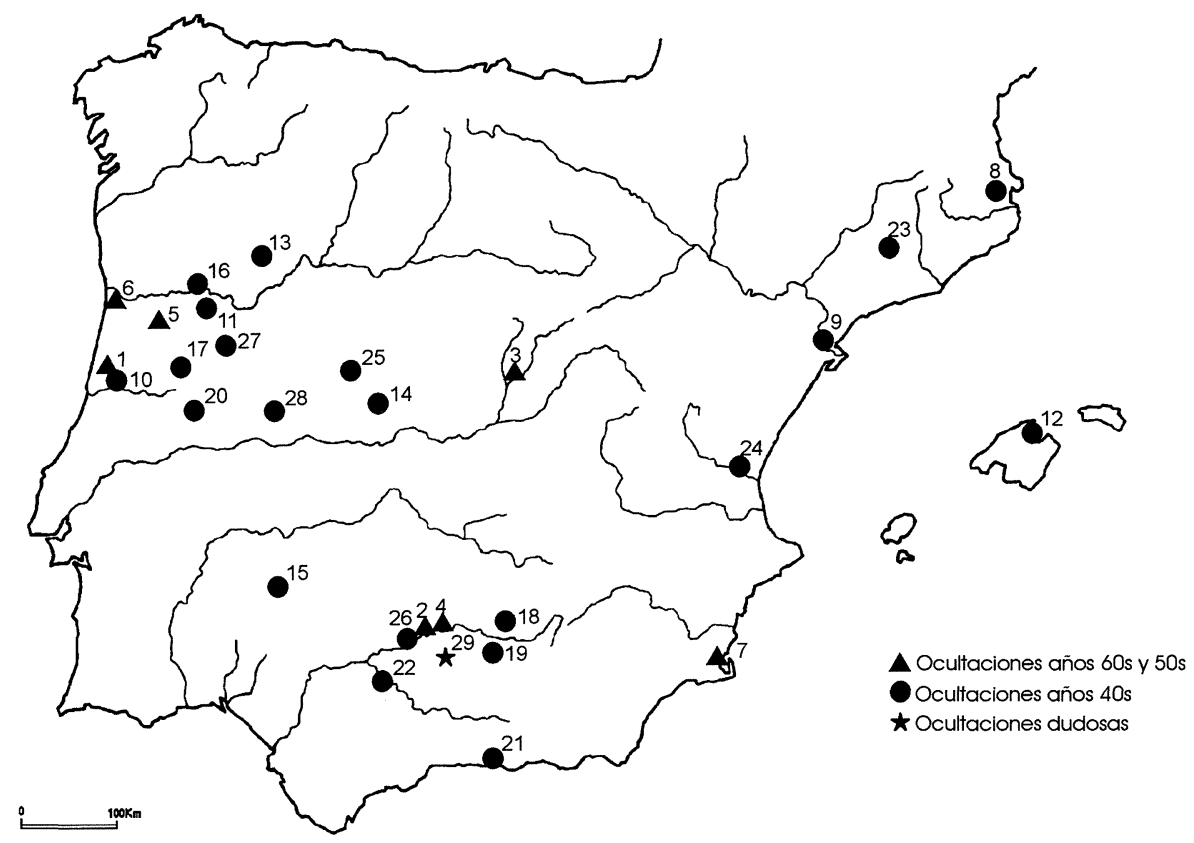

Fig. 1.- Tesoros atribuidos a la guerra entre pompeyanos y cesarianos: 1) Moita.- 2) Montoro I.- 3) Alcalá de Henares.- 4) Montoro II. 5) Calde.- 6) Valadares.- 7) La Grajuela.- 8) Figueras.- 9) Tortosa.- 10) Coimbra.- 11) Vilá de Rua.- 12) Son Siurana.- 13) Izeda.- 14) El Raso de Candeleda.- 15) Fuente de Cantos.- 16) Sâo Mamede de Ribatua.- 17) Sâo Bartolomeu de Meruge.- 18) El Centenillo.- 19) Jaén.- 20) Sedinho da Senhora.- 21) Almuñécar.- 22) Cortijo de Cosmes.- 23) Cataluña.- 24) Liria.- 25) Cerro del Berrueco.- 26) Córdoba.- 27) Menoita.- 28) Torre Milanera.- 29) Espejo.

llaronga 1987, 240) ${ }^{11}$, opinión que comparte Martini $(1988,66-69 ; 1989,23-25$. Faria 1993b, 144), quien reafirma lo anterior y considera que es de origen siciliano por razones tanto de carácter estilístico como de localización de los hallazgos.

De hecho, de los ases atribuidos a Pompeyo Magno en Hispania se documenta únicamente el hallazgo de dos en la zona costera de la Citerior, ambos RRC 479: uno en la necrópolis de Pollentia, en las Islas Baleares (Ripollès 1982, 130), y otro (partido) en Tarraco (Marot 1997, 147) ${ }^{12}$. Recientemente, en las excavaciones de la ciudad siciliana de Morgantina, esta emisión se ha encontrado en grandes cantidades, sobre todo las de mal arte ${ }^{13}$, lo cual, junto al hecho de que se encuentre en el mercado clandestino de Sicilia (Martini 1988, 67), parece

1 Grant $(1969,22)$ manifestó que estas piezas se encontraban en un número importante en la Península Ibérica, lo que las excavaciones arqueológicas no parecen demostrar (Martini 1988, 67)

${ }_{12}$ García-Bellido $(1996,253)$ menciona el hallazgo de un as (partido) RRC 479 en Oberaden y el de dos ases (uno partido) RRC 471 en Haltern, ambos campamentos militares situados en el limes germánico, a donde llegarían tropas legionarias previamente destinadas en Hispania, que serían las autoras del transporte de todas las piezas peninsulares encontradas.

13 Desde un punto de vista estilístico hay dos emisiones (Martini 1989, 25). indicar un origen insular de esta acuñación (RPC, p. 146) ${ }^{14}$.

Realmente, es cierto que la moneda RRC 478 es muy rara en la Península Ibérica ${ }^{15}$, pero puede aceptarse su procedencia de Hispania, sobre todo si se observa sus semejanzas con el as de su hermano Cneo (RRC 471; Amela 1990-1991, 190). Por lo que respecta al as RRC 479 se emitió, según varios investigadores (RRC, p. 487. Morawiecki 1983, 62), primeramente en Hispania y luego en Sicilia, sobre la base de diferencias de estilo, aunque otros (Grueber 1910,371 ) consideraban que la emisión fue realizada en su totalidad en Hispania.

Los estudios de Martini le han llevado a considerar que esta serie se acuñó totalmente en Sicilia, en tres momentos diferentes durante los años 43 a 36 a.C.: el primero posiblemente en Lilybaeum, mientras que los otros dos son por ahora desconocidos. Las monedas del primer y tercer periodo son de pobre estilo, que contrastan con las del segundo periodo, de buen arte, en la que se aprecia claramente

14 Se ha dicho igualmente que las monedas de buen estilo habrían sido acuñadas en Hispania, y las de mal estilo en Sicilia, como la RRC 479.

15 Kos $(1986,22)$ señala la probable influencia del bronce RRC 478 en la moneda nórica oriental del tipo Samobor $\mathrm{C} / 24$. 


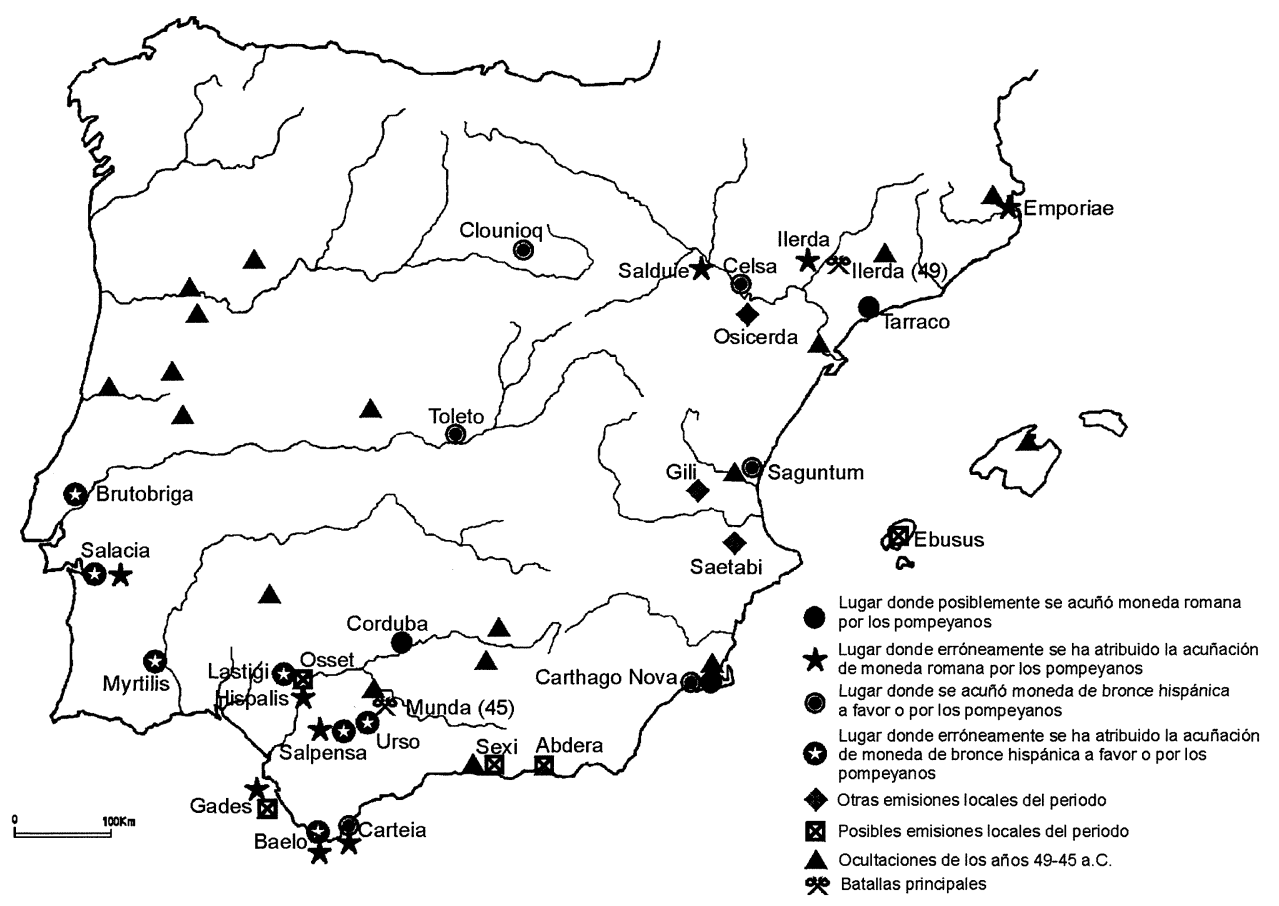

Fig. 2.- Geografía de la amonedación pompeyana en Hispania.

los rasgos de Pompeyo Magno en la representación de Jano (Martini 1988, 66; 1989, 25-26. RPC, p. 146$)^{16}$.

No deja de ser extraño que Martini sólo ponga en el banquillo la procedencia hispana de las monedas de bronce, mientras que no toma en consideración las monedas de plata acuñadas por Sexto Pompeyo en Hispania (y.en Sicilia). Muy posiblemente sea debido a que este investigador preferentemente estudia las acuñaciones de bronce de la época final de la República Romana, con el fin de determinar si existía una interrelación entre ellas, lo que lógicamente ha centrado toda su atención.

En cuanto a este punto, Buttrey (1960, 53-101) se ha ocupado de la acuñación del denario RRC 477 en Hispania, mientras que más recientemente Evans (1987, 97-157) ha estudiado las acuñaciones de plata y oro de Sexto Pompeyo en Sicilia ${ }^{17}$, sin que ninguno de ellos haya puesto en cuestión la atribución de la moneda de plata (más conocida como el dena-

16 Sear $(1998,204)$ considera que si bien la acuñación RRC 479 comenzó a emitirse antes de la ocupación de Sicilia a fines del año 43 a.C., su estilo es muy diferente de las acuñaciones de bronce pompeyanas anteriores a ésta, por lo que supone que debe tener un origen distinto, aunque admite que las diferentes variaciones de estilo de esta moneda se deberían a su largo periodo de emisión.

17 Para una nueva cronología de las acuñaciones sicilianas de Sexto Pompeyo, Woytek (1995, 79-94). rio de la Pietas de Sexto Pompeyo) a Hispania. Esto llama la atención, puesto que, si realmente se considera que las acuñaciones en bronce de Sexto Pompeyo no se realizaron en Hispania (sólo un tipo de las que Martini considera a este personaje a nombre de su hermano Cneo), sería muy raro que, por el contrario, acuñase monedas de plata.

Pero si bien en un principio se podría aceptar la teoría de Martini de considerar las emisiones de bronce de Sexto Pompeyo (atribuidas generalmente a Hispania) como efectivamente realizadas en Sicilia, este investigador atribuye igualmente el as RRC 471 , emitido a nombre de su hermano Cneo Pompeyo hijo (atribuido por la mayoría de investigadores a Hispania), como realmente acuñado por el propio Sexto Pompeyo (Martini 1988, 66; 1989, 23-24).

Martini $(1989,23-25)$ piensa que este bronce tuvo dos emisiones diferentes, una propiamente hispánica, entre los años 45-44 a.C., y otra gálica, en Massalia, donde Sexto Pompeyo se asentó después de su partida de Hispania en el año 44 a.C., a la espera de que se aclarase el panorama político de Roma. Esta diferencia (que espera confirme un análisis metalográfico) se basa en que las diferencias morfológicas, estilísticas y ponderales entre ambos grupos son demasiado grandes.

Para este investigador, un elemento decisivo para abandonar la atribución tradicional de Cneo Pompe- 
yo hijo es la elección del material para esta pieza, el bronce, pues considera que en los momentos anteriores a la batalla de Munda el partido pompeyano no estaba en situación de emitir este numerario. Por el contrario, Sexto Pompeyo, al considerar que no podría acuñar moneda de plata después del citado combate, se inclinaría por este material. Esto no es cierto, ya que Sexto Pompeyo, como su hermano mayor, acuñó denarios en la Península Ibérica (RRC 477). Las situaciones de Sexto Pompeyo y de Cneo Pompeyo hijo eran parecidas, por no decir idénticas, por lo que ambos debieron de buscar las mismas soluciones a sus problemas.

Ha de considerarse que si la moneda de bronce acuñada a nombre de Cneo Pompeyo hijo lo fue realmente por Sexto Pompeyo, habría que explicar la causa de ello. Martini $(1988,66)$ considera que lo realizó para conmemorar a su hermano caído después de la batalla de Munda, pero si era ésta su intención, realmente consiguió mejor su objetivo en una de sus acuñaciones sicilianas (RRC 511/1), en cuyo anverso representa a su padre y a su hermano, al igual que en el denario hispánico RRC 477/1a-b, en cuyo anverso aparece su hermano. En este mismo sentido, habría que preguntarse por qué no hizo lo mismo con su padre, Pompeyo Magno (Amela 1994, 35).

Quizás se pudiera pensar que Sexto Pompeyo, para no dar a conocer su existencia después del triunfo cesariano en Munda, emitiese moneda a nombre de su hermano. Apiano señala que en un principio Sexto Pompeyo no mencionaba quién era para pasar desapercibido (App. BCiv. 4, 83). Villaronga $(1967,133-142)$ hace tiempo que ha demostrado que éste acuñó moneda hispánica, en concreto la moneda bilingüe de Celsa, realizada para financiar sus andanzas por la parte septentrional de la Península Ibérica, quizás precisamente para este fin. Desde luego, si en sus emisiones hiciese referencia a su hermano desaparecido, difícilmente hubiera conseguido pasar desapercibido.

Por ello, es más lógico considerar que el bronce a nombre de Cneo Pompeyo hijo sea realmente atribuido a este personaje, y no a su hermano Sexto Pompeyo. En apoyo de este aserto, recientemente se considera (RPC, pp. 92, 19, 146, 161 y 180) que esta moneda fue acuñada en Hispania por Cneo Pompeyo hijo (quizás en Corduba) mientras que, por el contrario, se decanta por una solución siciliana en las otras dos piezas de bronce atribuidas a Sexto Pompeyo. Este punto puede servir de base para aclarar que, efectivamente, Sexto Pompeyo acuñó en la Península Ibérica monedas de bronce, pertenecientes a las series RRC 478 y 479, aunque con la posibilidad de que la segunda parte de sus emisiones se haya acuñado efectivamente en Sicilia.

Los ases son de una fábrica más ruda, posiblemente por ser una acuñación provincial (Grueber 1910, 371), al igual que el denario RRC 477 (Bernareggi 1963, 119-120). Sea como fuere, las acuñaciones en bronce de los hijos de Pompeyo prosiguen la tradición romana en cuanto a este tipo de moneda, tanto en su aspecto iconográfico, jurídico y de circulación (Martini 1989, 29), en un momento en que Roma precisamente no acuñaba este metal (Grueber 1910, 368)

La rareza de los ases pompeyanos en Hispania pudiera ser debida a que estas piezas fueran trasladadas fuera de la Península Ibérica. Apiano (App. $B C i v .4,85)$ informa de que Sexto Pompeyo, a la hora de ocupar Sicilia, procedente de Massalia, llevaba marinos de África e Hispania, y estaba bien provisto de oficiales, de naves, de soldados de infantería y de dinero, probablemente todo ello procedente en su mayor parte de Hispania (Tsirkin 1989, 145). Es decir, que quizás Sexto Pompeyo trasladase las monedas acuñadas en Hispania para el pago de sus tropas primero en Massalia y luego en Sicilia (Amela 1994, 36-37) ${ }^{18}$.

Pero lo anterior no parece muy posible, ya que el peso del transporte se multiplicaba por c. 120 (sobre la base del ratio $1 \mathrm{gr} \mathrm{Ag}=120$ gr AE; Zehnacker 1978,5$)$, por lo que su rendimiento sería muy dudoso ${ }^{19}$. Por tanto, la solución debe ser otra. Quizás se esté ante un caso paralelo a la abundantísima emisión cesariana de los años 49-48 a.C. (RRC 443/ 1), con 750 cuños de anverso y 833 de reverso, que pudo ser acuñada en Galia, Italia e Hispania, siguiendo los movimientos militares de César. Podría tratarse perfectamente de una auténtica ceca móvil, en razón de que la elección de los motivos utilizados en las series de bronce seguía siendo perfectamente válida en Sicilia.

Una solución al problema la puede aportar la acuñación de $Q$. Labienus Parthicus Imp. ${ }^{20}$ (RRC 524/1 áureo y 524/2 denario, del año 40 a.C.), la

${ }^{18}$ No hay que descartar que quizás parte de esta emisión se realizase en Massalia, puesto que Crawford (RRC, p. 94) atribuye a esta localidad la acuñación (o gran parte de ella) de Q. Nasidio en el año 44-43 a.C. (RRC 483/1-2), a lo que hay que unir la teoría de Martini sobre la procedencia de las acuñaciones pompeyanas en bronce.

19 García-Bellido $(1996,249)$ señala que los metales utilizados por las tropas para atesorar y transportar son el oro y la plata, como fácilmente se puede comprobar en los campamentos augusteos de Germania. Por tanto, Apiano debe aludir a piezas de estos metales cuando dice que Sexto Pompeyo estaba bien abastecido de dinero.

${ }^{20} \mathrm{Q}$. Labieno, hijo del general pompeyano T. Labieno, fue comisionado por el cesaricida C. Casio Longino a buscar apoyo entre los partos para luchar contra C. Octavio y Mar- 
cual, a pesar de haberse registrado únicamente 34 denarios y 3 áureos, ha dado un total de ocho cuños de anverso (ocho para el denario y dos para el áureo) y veintitrés de reverso (veinte para los denarios y tres para los áureos), lo que indica que a pesar del poco número de monedas conservadas la acuñación no debió ser precisamente pequeña (Hersh 1980, 47) ${ }^{21}$. Para Hersh, posiblemente aconteció que la acuñación fuese suprimida o fundida a la muerte de Labieno (39 a.C.), debido a su carácter fundamentalmente antirromano, como se puede comprobar fácilmente en su leyenda e iconografía. Quizás fuera éste el destino de gran parte de las monedas pompeyanas.

En este sentido, hay que tener un hecho en cuenta: se han encontrado monedas de «Divos Iulios» (RRC 535/1-2. RPC 620-621, de c. 38 a.C.) ${ }^{22}$ acuñadas tanto sobre piezas de Octavio de la ceca de Narbo (RPC 518) como de ases de Sexto Pompeyo (RRC 479; Collantes Pérez-Ardá 1987-1989, 49. RPC, p. 161), lo que también ha contribuido a que se encuentren pocos ejemplares de monedas hispanas de origen pompeyano, pues es la constatación de que los vencedores debieron de utilizar las emisiones pompeyanas para realizar sus propias series. En definitiva, parece constatarse una desmonetización de las emisiones pompeyanas.

Por ello, no parece que Sexto Pompeyo (ni su hermano Cneo) emitiesen moneda de bronce ante la dificultad de realizar acuñaciones en plata ${ }^{23}$, a causa de haberse «colapsado» la explotación de las minas de Sierra Morena (y quizás también las de los

co Antonio, de tal forma que en el año 40 a.C. invadió las provincias de Siria y Asia al frente de un ejército de este pueblo.

${ }^{21}$ Crawford (RRC, p. 529) da las siguientes cifras: cuños de anverso: $[<30]$, cuños de reverso: $[<33]$.

${ }^{22}$ Cfr.: Alföldi, A. y Giard, J.-B., «Guerre civile et propagande politique: l'emission d'Octave au nom du Divos Julius (41-40 avant J.C.)», QT, 13, 1984, 147-153. Martini, R., Monetazione bronzea romana tardo-repubblicana. I. Divos Iulius di Octavianus, "assi» di Sextus Pompeius, emissioni dei prefetti di Antonius, Milano, 1988; «Note sulla distribuzione delle emissioni bronzee del «Divos Iulius»», Notizie dal chiostro del Monastero Maggiore, 41-42, 1988, 39-42. Esta acuñación probablemente sea una respuesta de Octavio a las emisiones contemporáneas de bronce de Sexto Pompeyo (Burnett 1987, 36 y 52).

${ }^{23}$ Grueber $(1910,368)$ señala la gran abundancia de este metal en la Bética, gracias a sus ricas minas, y en análisis metalífero de estas piezas se ajusta a la descripción realizada por Plinio sobre el Aes Cordubense (Plin. NH 34, 2). Domergue $(1990,194-196)$ señala que las minas de plata eran las que en mayor número se encontraban en explotación en la Península Ibérica a finales de la República, de tal manera que al celebrar César en el año 45 a.C. su triunfo sobre Hispania, los emblemas utilizados eran de plata pulida, así como por ejemplo sobre Alejandría eran de escamas de tortuga y en el de África de marfil (Vell. Pat. 2, 56, 2). alrededores de Carthago Nova) durante la guerra civil ${ }^{24}$, a lo que habría que sumar las diversas exacciones que realizaron tanto pompeyanos como cesarianos (Amela, 1990-1991, 36; 1994, 36).

Evidentemente, las acuñaciones de bronce (de un patrón teórico de 22 gramos, como el antiguo sistema uncial; Collantes Pérez-Ardá 1987-1989, 49) se realizaron gracias a la abundancia de este metal, con la clara voluntad de vulnerar la lex Papiria (91/90 a.C.; Zehnacker 1978, 7. Martín 1989, 29. Sear 1998,139 y 204), con la evidente finalidad de pagar los gastos derivados de la guerra (Burnett 1987, $52)^{25}$, como así fueron las acuñaciones bilingüies de Celsa ${ }^{26}$, o incluso de llevar a término una reforma monetaria, que no pudo finalmente realizarse (Martini 1989,29$)^{27}$.

${ }^{24}$ Así lo parecería indicar la destrucción del poblado minero de Diógenes y de la fundición del Cerro del Plomo en El Centenillo (prov. Jaén; Blázquez 1978, 41. Domergue 1987, 83 y $270-271 ; 1990,188)$, En cambio, García-Bellido (1982, 114) y Arévalo González $(1999,175)$ consideran que el abandono de Diógenes se ha de fechar en la guerra sertoriana.

${ }_{25}$ Desde luego, las legiones de Sexto Pompeyo que Cicerón describe en la Hispania meridional (Cic. Att. 10, 4, 2), reclutadas en su mayor parte entre los supervivientes de las campañas de su padre y su hermano en Hispania (App. BCiv. $4,83)$, debían percibir sus respectivas pagas. El denario RRC 477 es buena prueba de ello.

26 Villaronga $(1967,140-141 ; 1987,240)$ relacionó el peso de los ases emitidos en Hispania por los pompeyanos, todos de peso alto, con los ejemplares bilingües de Celsa, y señaló que, si bien generalmente se había interpretado el peso de estas piezas como una anomalía atribuida a una ceca provincial, en realidad lo que se intentaba era buscar el patrón de peso de los denarios para utilizar este numerario como soldada, quizás como un síntoma de agotamiento de las minas de plata de la Bética o de su difícil explotación debido al desarrollo del conflicto. La relación metrológica entre la emisión bilingüe de Celsa y los bronces pompeyanos hispanos es la siguiente:

- peso medio emisión RRC 471 (46-45 a.C.): 20’92 gr - peso medio emisión RRC 479 (45-44 a.C.): 21'45 gr - peso medio emisión RRC 478 (45-44 a.C.): 17'27 gr - peso medio emisión KELSE-CEL (45-44 a.C.): 16'43 gr - peso medio emisiones Colonia Lépida (44-43 a.C.): 15 '49 a 13'16 gr en descenso progresivo.

27 Existe una serie de emisiones de ciudades sicilianas de época triunviral cuyo standard metrológico es alto, con, aproximadamente, ases de $19 \mathrm{gr}$ (Henna [RPC 661], $\mathrm{Li}$ lybaeum [RPC 655]), semises de 8 gr (Henna [RPC 662], Assorus [RPC 665], Segesta [RPC 648-650]), trientes (o cuadrantes) de 5 gr (Henna [RPC 663], Assorus [RPC 666], Segesta [RPC 651], Lipara [RPC 626], Melita [RPC 672674]) y sextantes de 2' 5 gr (Henna [RPC 664]). El peso de los ases está en relación con los emitidos por Sexto Pompeyo (RPC, pp. 165-166). De lo anterior pudiera deducirse que se trata de un sistema propiamente siciliano si no existiera la acuñación de bronce de Cneo Pompeyo hijo (RRC 471), del mismo patrón metrológico, probable explicación de que Martini considere esta última emisión como siciliana. Pudiera tratarse de un sistema impuesto en Sicilia por Sexto Pompeyo, cuyos ensayos se hubieran realizado previamente en Hispania, aunque hay que tener en cuenta que varios investigadores atribuyen algunas de las piezas anteriores (concretamente de Assorus y Henna) c. 200 a.C. (RPC Suppl., p. 14) 


\begin{tabular}{|c|c|c|c|c|c|}
\hline Fecha & RRC & Monetarios & Lugar & Valor & Bando \\
\hline 49 & $440 / 1$ & Q. SICINIUS IIIVIR & Roma & denario & pompeyano \\
\hline 49 & $441 / 1$ & NERI Q.URB & Roma & denario & pompeyano \\
\hline 49 & $442 / 1$ & MN. ACILIUS IIIVIR & Roma & denario & cesariano \\
\hline 49 & $443 / 1$ & CAESAR & Galia, luego Hispania & denario & cesariano \\
\hline 49 & $444 / 1$ & Q. SICINIUS IIIVIR/C. COPONIUS PR & Móvil con Pompeyo & denario & pompeyano \\
\hline 49 & $445 / 1-3$ & L. LENTULUS C. MARC COS & Apollonia, luego Éfeso & denario & pompeyano \\
\hline 49 & $446 / 1$ & MAGN PROCOS con CN PISO PROQ & Hispania & denario & pompeyano \\
\hline 49 & $447 / 1$ & MAGN PROCOS con VARRO PROQ & Hispania & denario & pompeyano \\
\hline 48 & $448 / 1-3$ & L. HOSTILIUS SASERNA & Roma & denario & cesariano \\
\hline 48 & $449 / 1-4$ & C. VIBIUS C.F. C.N. PANSA & Roma & denario & cesariano \\
\hline 48 & $449 / 5$ & C. VIBIUS C.F. C.N. PANSA & Roma & sestercio & cesariano \\
\hline 48 & $450 / 1-3$ & ALBINUS BRUTI F. & Roma & denario & cesariano \\
\hline 48 & $451 / 1$ & ALBINUS BRUTI F. C. PANSA & Roma & denario & cesariano \\
\hline $48-47$ & $452 / 1$ & CAESAR & Móvil con César & áureo & cesariano \\
\hline $48-47$ & $452 / 2$ y 45 & CAESAR & Móvil con César & denario & cesariano \\
\hline $48-47$ & $452 / 3$ & CAESAR & Móvil con César & quinario & cesariano \\
\hline 47 & $453 / 1$ & L. PLAUTIUS PLANCUS & Roma & denario & cesariano \\
\hline 47 & $454 / 1-2$ & A. LICINIUS NERVA IIIVIR & Roma & denario & cesariano \\
\hline 47 & $454 / 3$ & A. LICINIUS NERVA IIIVIR & Roma & quinario & cesariano \\
\hline 47 & $454 / 45$ & A. LICINIUS NERVA IIIVIR & Roma & sestercio & cesariano \\
\hline 47 & $455 / 1-2$ & C. ANTIUS C.F. RESTIO & Roma & denario & cesariano \\
\hline 47 & $455 / 3$ & C. ANTIUS C.F. RESTIO & Roma & quinario & cesariano \\
\hline 47 & $455 / 4-6$ & C. ANTIUS C. F. RESTIO & Roma & sestercio & cesariano \\
\hline 47 & $456 / 1$ & CAESAR DICT. ITER & Oriente & áureo & cesariano \\
\hline 47 & $457 / 1$ & A. ALLIENUS PRO COS & Lilybaeum? & denario & cesariano \\
\hline $47-46$ & $458 / 1$ & CAESAR & Africa & denario & cesariano \\
\hline $47-46$ & $459 / 1$ & Q. METEL. PIUS SCIPIO IMP. & Africa & denario & pompeyano \\
\hline $47-46$ & $460 / 1$ & Q. METEL. PIUS SCIPIO IMP. cOn P. CRASSUS IUN.LEG.PROPR & Utica & áureo & pompeyano \\
\hline $47-46$ & $460 / 2-3$ & Q. METEL. PIUS SCIPIO IMP. con P. CRASSUS IUN.LEG.PROPR & Utica & denario & pompeyano \\
\hline $47-46$ & $461 / 1$ & Q. METEL. PIUS SCIPIO IMP. con EPPIUS LEG.F.C. & Africa & denario & pompeyano \\
\hline $47-46$ & $462 / 1$ & M. CATO PROPR & Utica & denario & pompeyano \\
\hline $47-46$ & $462 / 2$ & M. CATO PROPR & Utica & quinario & pompeyano \\
\hline 46 & $463 / 1-3$ & MN. CORDIUS RUFUS IIIVIR & Roma & denario & cesariano \\
\hline 46 & 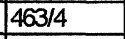 & MN. CORDIUS RUFUS IIIVIR & Roma & quinario & cesariano \\
\hline 46 & $463 / 5-6$ & MN. CORDIUS RUFUS IIIVIR & Roma & sestercio & cesariano \\
\hline 46 & $464 / 1-5$ & T. CARISIUS IIIVIR & Roma & denario & cesariano \\
\hline 46 & $464 / 6$ & T. CARISIUS IIIVIR & Roma & quinario & cesariano \\
\hline 46 & $464 / 7-8$ & T. CARISIUS IIIVIR & Roma & sestercio & cesariano \\
\hline 46 & $465 / 1-5$ & C. CONSIDIUS PAETUS & Roma & denario & cesariano \\
\hline 46 & $465 / 6-7$ & C. CONSIDIUS PAETUS & Roma & quinario & cesariano \\
\hline 46 & $465 / 8$ & C. CONSIDIUS PAETUS & Roma & sestercio & cesariano \\
\hline 46 & $466 / 1$ & A. HIRTIUS PR, C. CAESAR COS.TER & Roma & áureo & cesariano \\
\hline 46 & $467 / 1-2$ & COS.TERT.DICT.ITER. AUGUR PONT.MAX. & Utica? & denario & cesariano \\
\hline $46-45$ & $468 / 1$ & CAESAR & Hispania & denario & cesariano \\
\hline $46-45^{*}$ & $469 / 1$ & CN. MAGNUS IMP, M.POBLICI.LEG.PROPR & Corduba & denario & pompeyano \\
\hline $46-45^{\star}$ & $470 / 1$ & CN. MAGNUS IMP.F, M.MINAT.SABIN.PR(O)Q & Corduba & denario & pompeyano \\
\hline $46-45^{\star}$ & $471 / 1$ & CN.MAG.IMP & Corduba & as & pompeyano \\
\hline 45 & $472 / 1-2$ & L. PAPIUS CELSUS IIIVIR & Roma & denario & cesariano \\
\hline 45 & $472 / 3$ & L. PAPIUS CELSUS IIIVIR & Roma & quinario & cesariano \\
\hline 45 & $472 / 4$ & L. PAPIUS CELSUS IIIVIR & Roma & sestercio & cesariano \\
\hline 45 & $473 / 1-2$ & PALIKANUS & Roma & denario & cesariano \\
\hline 45 & $473 / 3$ & PALIKANUS & Roma & quinario & cesariano \\
\hline 45 & $473 / 4$ & PALIKANUS & Roma & sestercio & cesariano \\
\hline 45 & $474 / 1-5$ & L. VALERIUS ACISCULUS & Roma & denario & cesariano \\
\hline 45 & $474 / 6$ & L. VALERIUS ACISCULUS & Roma & quinario & cesariano \\
\hline 45 & $4747-8$ & L. VALERIUS ACISCULUS & Roma & sestercio & cesariano \\
\hline 45 & $475 / 1$ & L.PLANC.PRAEF.URB, C.CAESAR.DIC.TER & Roma & áureo & cesariano \\
\hline 45 & $475 / 2$ & L.PLANC.PRAEF.URB, C.CAESAR.DIC.TER & Roma & medio áureo & cesariano \\
\hline 45 & $476 / 1$ & C.CLOVI.PRAEF, CAESAR DIC.TER & Roma & dupondio? & cesariano \\
\hline $45-44$ & $477 / 1-3$ & SEX.MAGNUS PIUS IMP & Hispania & denario & pompeyano \\
\hline $45-44$ & $478 / 1$ & MAGNUS PIUS IMP.F, EPPIUS LEG & Hispania & as & pompeyano \\
\hline desde 45 & $479 / 1$ & MAGNUS PIUS IMP & Hispania, luego Sicilia & as & pompeyano \\
\hline
\end{tabular}

Cuadro.-Acuñaciones romanas del periodo de la Segunda Guerra Civil (según Crawford, con correcciones de Sear). 
Esto parecería confirmarse en el hecho de que, siguiendo una antigua costumbre en las pagas del ejército, el as tendría el valor de $1 / 10$ del denario (Plin. NH 33, $45^{28}$; Collantes Pérez-Ardá 1987$1989,37-38)$ y no de un $1 / 16$, como era en este momento ${ }^{29}$ : si el denario de plata equivalía en estas fechas a 16 ases de $10^{\prime} 92$ gr, representa un total de $174^{\prime} 77$ gr, que, repartidos entre 10 ases, da un valor al as de $17^{\prime} 47$ gr. Éste debió de ser seguramente el peso medio del bronce que se está comentando (Villaronga 1967, 140).

El problema planteado es que si estas acuñaciones hubieran servido como stipendium para la tropa ${ }^{30}$, al ser sobre la base de $1 / 10$ y no de $1 / 16$, el sistema sería ventajoso para los soldados si se cobrase en plata, pero no en bronce, puesto que en la vida civil se hubieran necesitado dieciséis ases para conseguir un denario, es decir, que se habría perdido más de un $30 \%$ en el poder adquisitivo.

Posiblemente, las monedas de bronce servirían como moneda fraccionaria (Knapp 1982, 197) para uso cotidiano, la cual era escasa en este tiempo. En este sentido, conviene recordar la emisión de cuadrantes a nombre de Cn. Iuli(us) L. f(ilius) $q$ (uaestor), emitidos a favor de Q. Cecilio Metelo Pio durante la guerra sertoriana en Corduba, su cuartel general (Chaves 1980-1981, 7-9; 1991-1993, $273 ; 1998,257$ y 302. Crawford 1985, 347) ${ }^{31}$.

${ }^{28}$ Cfr.: Nicolet, C., «Les variations des prix et la «théorie quantitative de la monnaie» à Rome, de Ciceron à Pline l'Ancien», Annales(ESc), 26, 1971, 1203-1227; «Pline, Paul et la théorie de la monnaie», Athenaeum, 62, 1984, 105-135. Zehnacker, H., «Pline l'Ancien et l'histoire de la monnaie romaine», Ktèma, 4, 1979, 169-181.

${ }^{29}$ Durante la primera mitad del s. II a.C., la soldada se hacía efectiva en moneda de bronce, hasta que fue sustituida por el denario de plata, cuya principal repercusión en Hispania fue la aparición del denario ibérico.

${ }^{30}$ Cfr.: Gabba, E., «Aspetti economici e monetali del soldo militare del II sec. a.C. al II sec. d.C.», en Les dévaluations à Rome. Epoque républicaine et impériale Rome, 1978, 217-225. Giovannini, A., «Le solde des troupes romaines à l'époque républicaine», $M H, 35,1978,258-263$. Frier, B. W., «Roman coinage and army pay: technics for evaluating statistics», $Q T, 10,1981,285-295$. Boren, H. C., «Studies reading to the stipendium militum», Historia, 32, 1983, 427-460. Zehnacker, H., «La solde de l'armée romaine, de Polybe a Domitien», AIIN, 30, 1983, 95-121. Lo Cascio, E., «Ancora sullo stipendium legionario dall'età polibiana a Domiziano», AIIN, 36, 1989, 101-120. Alston, R., «Roman Military Pay from Caesar to Diocletian», JRS 84, 1996, 113-123.

${ }^{31}$ Esta cronología es más aceptable que la época del conflicto entre César y Pompeyo Magno (Grant 1969, 4-7, 455 y 461) o el siglo II a.C. (Villaronga, 1981, 280; 1994, 203. Knapp 1982, 187). Estas acuñaciones se encuentran en los tesoros del periodo sertoriano de Azaila II, Borriol, Castra Caecilia y Puebla de los Infantes (de los que forman monográficamente su composición), así como en numerosos castra extremeños del momento. En este mismo sentido, este mismo conflicto bélico sería el responsable, por la rápida necesidad de numerario, de la mayor parte de las reacuñaciones
Aparte del propio Sexto Pompeyo, a cuyo nombre se realizaron estas monedas, el único magistrado monetal que se encuentra, como responsable de éstas, es M. Eppius M.f. Ter., un homo novus (Wiseman, 1971, 229), quien, curiosamente, en vez de figurar en el denario, aparece en una acuñación de bronce (RRC 478), aunque Grant $(1969,22)$ lo hace igualmente responsable de la otra serie de bronce, la RRC 479, lo cual es probable pero indemostrable.

Eppio, senador (Cic. Fam. 8, 8, 5-6) ${ }^{32}$, tomó parte muy activa en favor de Pompeyo Magno durante la guerra civil de los años 49-44 a.C. Fue uno de los legados de Q. Cecilio Metelo Pio Escipión en la campaña de África durante los años 47-46 a.C., en la que se le encomendó también la emisión de una moneda, esta vez de plata, con su nombre, Eppius leg. $f$. c.: Eppius legatus flandum curaverunt (RRC $461 / 1)^{33}$. Este mismo cargo de legado es el que se encuentra en la acuñación de Sexto Pompeyo. Eppio fue perdonado por César después de la batalla de Thapsus (BAfr. 89, 5), aunque se conoce que luego actuó de nuevo como legado pompeyano, esta vez de Sexto Pompeyo, con la misma misión de acuñar moneda ${ }^{34}$. Se desconoce qué fue de él después de esta amonedación.

Sexto Pompeyo, como anteriormente su hermano, Cn. Pompeyo hijo, acuña plata con el busto de su padre pero, a diferencia de éste, no hace referencia a acontecimientos ocurridos en la Península Ibérica (RRC 469-470). La proa de nave que aparece en el reverso de las monedas de bronce posiblemente haga mención a la flota de Sexto Pompeyo (App.

locales de bronce conocidas pertenecientes a la Hispania Ulterior (Crawford 1985, 347. Ripollès 1995, 292-295. Alfaro Asins 1996, 31), así como de moneda romano-republicana (Arévalo y Marcos, 1997, 71). Igualmente hay que señalar la fabricación durante este periodo de imitaciones anónimas de monedas de bronce romanas (mayormente semises), acuñadas en la Península Ibérica, especialmente en la Ulterior (como muestra el tesoro del río Guadalete), que fueron toleradas por las autoridades y cuya finalidad era la de cubrir una circulación deficiente, seguramente para el cambio de moneda fraccionada para las tropas que operaban en los escenarios bélicos (Villaronga 1985, 39. Knapp 1987, 30. Marcos Alonso 1989, 444-445; 1996, 200 y 209-211), aunque Chaves $(1993,124 ; 1999,315)$ cree que podría tratarse de un grupo de inmigrantes itálicos que no formasen parte de una ciudad indígena que amonedase, que necesitaban un numerario menor para realizar pequeños pagos.

32 Broughton $(1952,236)$ y Wiseman $(1971,229)$ lo consideran quaestor del año 52 a.C., por ser mencionado en la correspondencia del año 51 a.C. como senador, sin conocérsele otro cargo electo.

${ }^{33}$ Crawford (RRC, p. 472) y Sear $(1998,33)$ consideran que el título de Epio sería legatus fisci castrensis y no la solución tradicional legatus faciendum (o fiandum) curavit, debido a que esta expresión no refleja una magistratura.

${ }^{34}$ Broughton (1952, 301 y 331) lo califica como legado durante la guerra civil. 
BCiv. 4, 84), motivo que aparece igualmente en la amonedación de su hermano Cneo (RRC 471), aunque también puede que simplemente reviva el tradicional tipo romano para estas monedas (Carson 1978, 65. RPC, p. 146. Arévalo y Campo 1998, 320. Sear 1998,37 y 205) ${ }^{35}$. Pero, sobre todo, estas piezas informan de la ideología de este personaje.

Es de destacar la labor de Sexto Pompeyo en el sentido de que, mediante el recuerdo de su padre y de su hermano, pretendiese consolidar la simpatía y colaboración de sus partidarios. En efecto, en el denario RRC 477/1a-b se puede apreciar que figura la cabeza de Pompeyo Magno ${ }^{36}$, que en la moneda RRC 477/2 y 3a-b es sustituida por la de su hermano Cneo (Battenberg 1980, 100. Morawiecki 1983, 62-63).

Así, la aparición de la cabeza del dios Jano (presente ya en el as de Cneo Pompeyo hijo, RRC 471) muestra un adecuado compromiso entre las ambiciones de Sexto Pompeyo y los ideales republicanos (Grant, 1969, 23. Campo 1972, 64), destacando que en la moneda RRC 479 Jano encubre realmente la figura de Pompeyo Magno (Alföldi 1956, 78. Zehnacker 1965, 287. Battenberg 1980, 100-101. Morawiecki 1983, 62), que no es más que una anticipación del concepto del divi filius de Augusto (Alföldi 1956, 78. Burnett 1987, 52). Es bastante normal encontrar en las emisiones de esta época la reaparición de muchos de los dioses del panteón romano (RRC, p. 737), aunque se ha dicho que la representación de Jano, ligado a las ideas de la guerra y la paz, significaría que por un lado se haría la guerra a los enemigos de la república, mientras que se ofrecía la paz a los ciudadanos de buena voluntad (Zehnacker 1965, 288-289).

Morawiecki $(1983,64)$ señala que el tan contraído compromiso puesto de manifiesto por Grant es un poco difícil de discernir, puesto que atribuir a Pompeyo Magno los rasgos de un dios (en este caso Jano) no parece ser lo que se pudiera considerar muy republicano, y a lo que se está asistiendo es al nacimiento y consolidación de un culto hacia los Pompeyos que, en verdad, no es otra cosa que un culto al propio Sexto Pompeyo, más conocido en otras acuñaciones suyas como el hijo de Neptuno (Dio Cass. 48, 19, 2), cuya representación plástica

${ }^{35}$ Quizás este motivo (derivado de los primeros ases acuñados por Roma después de la gran reforma monetaria de c. 211 a.C.) se debiese a asegurar la aceptación de estas piezas acuñadas fuera de Roma. No debe olvidarse que estos ases presentan en el anverso la cabeza de Jano bifronte y en el reverso una proa de nave, es decir, la descripción de las acuñaciones de los hijos de Pompeyo Magno RRC 471, 478 y 479.

${ }_{36}$ Sobre las representaciones plásticas de Pompeyo Magno, cfr. Michel (1967, 35-66) sería la acuñación de Q. Nasidio para Sexto Pompeyo (RRC 483) ${ }^{37}$.

La imagen de la Piedad hace alusión tanto al sobrenombre de Sexto Pompeyo, Pius, como a los Manes de los Cneos (su padre y su hermano) y a los deseos de venganza de éste (Grueber 1910, 371. Alföldi 1956, 89. Bernareggi 1963, 119. Seaby 1967, 104. Grant 1969, 23. Weinstock 1971, 254. Campo 1973, 61. RRC, p. 739. Battenberg, 1980, 100. Evans 1987, 104. Morawiecki 1983, 64. Alteri 1990, 96), y que ya dejó claro Cicerón en su momento (Cic. Phil. 5, 39): ... duos Cn. Pompei... filios... quibus certe pietas fraudi esse non debuit. También hay que tener en cuenta que la pietas de Sexto Pompeyo contrastaba con la propagada por César (Weinstock 1971, 254. Battenberg 1980, 100). Pietas era la divisa de los Metelli, que fue plagiada por sus aliados y adoptada como consigna de los pompeyanos en la batalla de Munda (App. BCiv. 2, 104. Syme 1958, 174).

Evidentemente, Pius (que significa literalmente «obediente» o «devoto») no es sólo un simple cognomen, como en su día defendió Syme, sino que está en estrecha relación con el concepto de pietas, que en este caso no expresa la pietas erga patriam, sino exclusivamente la pietas erga parentem et fratrem, mostrando un deseo de vengar la muerte de su padre y de su hermano, el mantenimiento de la dignitas de su gens (Hadas 1930, 152. Battenberg 1980, 101. Morawiecki 1983, 64. Evans 1987, 104. Alteri 1990, 96. Sear 1998, 137). Es de destacar que la mención (RRC 477/3) o no (RRC 477/1-2) de Pius en las acuñaciones de plata (Sextus Magnus Imperator versus Sextus Magnus Pius Imperator) permite dividir las acuñaciones de Sexto Pompeyo en dos fases claramente diferentes (Sear 1998, 137).

Mucho más interesante es la interpretación que se ha dado al letrero IMP SAL del denario RRC 477: imperator salutatus (Grueber 1910, 371) o imperator salutatis (Toynbee 1978, 24), construcción nada corriente (Buttrey 1960, 90-91) ${ }^{38}$, mientras que para otros $S A L$ sería la inicial de la ceca emisora (Buttrey 1960, 96-97. Combes 1966, 131. Gil Farrés 1966, 334 y 370. Banti y Simonetti 1972, 238. Morawiecki 1983, 64). Sobre el título imperator, Grant (1910, 371) menciona que no se conoce ninguna noticia a través de las fuentes literarias de que Sexto Pompeyo asumiera o recibiera durante este tiempo el títu-

${ }^{37}$ Cfr. La Rocca (1987-1988, 265-292). Los denarios de Sexto Pompeyo prefiguran la amonedación imperial, en cuyo anverso se reproduce el aspecto físico y en el reverso el aspecto moral (Herrero 1994, 227).

${ }^{38}$ Lo normal sería imperator appellatus (Caes. BCiv. 2, 26, 1. Cic. Phil. 14, 11. Liv. 7, 39, 15. Val. Max. 2, 8, 7). 
lo de imperator, aunque lo pudo tomar inmediatamente después de la muerte de su hermano, al coger el mando de los restos del ejército pompeyano. Otros investigadores (Babelon 1885, 349. Hadas 1930, 58. Bernareggi 1963, 120. Evans 1987, 104) suponen que lo habría obtenido después de derrotar a C. Asinio Polión, gobernador cesariano de la Hispania Ulterior (App. BCiv. 4, 83. Dio Cass. 45, $10,1-3)$.

Es más lógico que lo tomase después de la derrota de Asinio Polión, ya que Sexto Pompeyo, después de Munda, tuvo que huir a la Celtiberia y luego a la Lacetania como un simple prófugo, escondiendo su nombre, por lo que muy difícilmente puede asumirse que en esta época se hiciera denominar imperator.

En realidad, el apelativo imperator no sólo alude al vencedor de una confrontación militar, sino que va más allá. Así, a través de las monedas, Buttrey $(1960,87)$ considera que el apelativo imperator sería en realidad el verdadero praenomen de Sexto Pompeyo. Por contra, para Syme (1958, 175-177) la leyenda Imp. Sex. Magnus demostraría que imperator no se convirtió en el praenomen, sino que como máximo iría unido a él y, desde luego, no lo sustituyó ${ }^{39}$.

Imperator forma parte realmente del nombre propio de Sexto Pompeyo. El primero en utilizar este sistema fue Pompeyo Magno, a quien, en una inscripción de Auxinum, en el Piceno, se designa como Cn. Pompeius Cn.f. Magnus imp., fechada en el año 52 a.C. (CIL I ${ }^{2}$ 769. CIL IX 5837. ILLRP 382. ILS 877) ${ }^{40}$, nueve años después de su último triunfo (el tercero, contra los piratas y Mitrídates VI de Ponto), en un acto oficial de una comunidad, lo que indica que este sistema ya era reconocido (Syme 1958, 178). Varios generales de diferentes bandos que se enfrentaron en las guerras civiles que ensangrentaron la República Romana añadieron libremente imp(erator) a sus nombres, siendo una notable excepción la del constitucionalista M. Porcio Catón. No todas ellas reflejaban el derecho a la autoridad legal, sino que para este estudioso muchas de estas titulaciones no derivarían de una victoria sino de un acto de usurpación, lo que significaría no sólo la reclamación del derecho al triunfo un día sino también un título de autoridad y mando. De esta forma, Sexto Pompeyo tomaría el título imp. cuando alzó el estandarte pompeyano en la Hispa-

${ }^{39}$ Sexto Pompeyo se hace designar como Mag. Pius Imp. iter en su áureo (RRC 511/1) y sus denarios (RRC 511/2-4) sicilianos.

${ }^{40}$ [CN. P]OMPEIO CN. [F.] / [MA]GNO IMP. COS TER. / [PA]TRONO PUBLICE. nia Citerior, y no cuando derrotó posteriormente a Asinio Polión en la Hispania Ulterior. Es decir, que la palabra imperator se convirtió en la acepción para «líder» o «comandante» (Syme 1958, 180-181. Weinstock 1971, 110-111) ${ }^{41}$.

Igualmente, en la titulatura de Sexto Pompeyo se sigue utilizando el cognomen de su padre, Magnus, al igual que su hermano, de tal forma que se convirtió en un elemento más importante que el propio praenomen, al que finalmente substituye (Morawiecki 1983, 64). Syme (1958, 174-175) señala que en una conferencia celebrada el uno de enero del año 43 a.C. Cicerón califica a Sexto Pompeyo como Sextus Pompeius Gnaei filius Magnus (Cic. Phil. 5, 41), mientras que a finales de marzo en un esbozo de un senatus consultum lo designa como Magnus Pompeius, Gnaei filius (Cic. Phil. 13, 50), es decir, que Magnus se ha convertido en el praenomen. Su nombre, Sextus Magnus Pius, en términos de estricta nomenclatura, habría que interpretarlo como praenomen, nomen y cognomen, es decir, que Magnus se ha promovido al rango de nombre familiar. Ya en Sicilia las monedas revelan finalmente que se denomina Magnus Pius (RRC 511), como lo prueba una inscripción procedente de Lilybaeum (AE 1895 23. ILS 8891. ILLRP 426) ${ }^{42}$.

El proceso es evidente: Sexto Pompeyo ha descartado desde hace tiempo el praenomen Sextus y el «experimento» de Magnus como nomen, como se puede apreciar que el Sextus Magnus Pius de su acuñación hispánica no se ha repetido, apareciendo ya en Sicilia la nomenclatura Magnus Pius, del tipo praenomen + cognomen (aunque esto ya se pudo haber dado en la Península Ibérica si se consideran las monedas de bronce) ${ }^{43}$. En definitiva, si bien el nombre de su hermano, Cn. Magnus, es impecable, el de su hermano Sexto Pompeyo es ya revolucionario y presagia la monarquía (Syme 1958, 175), que se plasmará en la nomenclatura Imp. Caesar Augustus (Syme 1958, 188).

Es muy interesante considerar que el nombre de Imperator (Imperator Caesar), que llevarán los sucesivos emperadores romanos a partir de Octavio, no es más que una réplica del Magnus de Sexto

${ }^{41}$ Grant $(1969,22)$ considera que la mención de IMP. no debe interpretarse como una distinción personal (por sus victorias militares), sino como el título de un imperium especial hereditario, que se podría observar tanto en las monedas de Cneo Pompeyo hijo (RRC 469-471) como de Sexto Pompeyo (RRC 477-479).

42 MAG. POMPEIO MAG. F. PIO IMP. AUGURE / COS. DES. POR[TA]M ET TURRES / L. PLINIUS L. F. RUFUS LEG. PRO PR. PR. DES. F. C.

${ }^{43}$ Evans $(1987,104)$ opina que los agnomina Magnus Pius han de ser considerados como el nomen y cognomen de Sexto Pompeyo. 
Pompeyo, es decir, que el nombre del hijo más joven de Pompeyo Magno sirvió como modelo para la titulación de los emperadores romanos, aunque el Imperator no es un título de autoridad, sino algo ya místico, una monopolización de la gloria del triumphator, pero nunca un nombre personal. Imperator Augustus no es más que un paralelo de Magnus Pius y, en el momento en que aparece la fórmula de Caesar Augustus o Augustus Caesar Imperator, se convierte realmente en un praenomen (Syme 1958, 182-183), es decir, que el nombre completo no es más que un ejemplo de tria nomina (Syme, 1958, 187).

Sobre el lugar de emisión de estas monedas existe una amplia problemática relativa a la leyenda $S A L$ que aparece en el denario, que no sería un apelativo que acompañaría a $I M P$, sino la abreviatura de la ceca de emisión, como anteriormente se ha mencionado. De esta forma, se han propuesto las ciudades de Salduie (Untermann 1975, 213), Salacia (Beltrán Martínez 1950, 373. Gil Farrés 1966, 334 y 370. Grant 1969, 23-24. Faria 1988, 79-80; 1996, 117. Gomes $1996^{2}$, 39) y Salpensa (Buttrey 1960, 86-87 y 97. RRC, p. 94) como las localidades donde se emitió esta moneda.

Varios investigadores ${ }^{44}$ defienden que tanto el apelativo Imperatoria (Urbs Imperatoria Salacia, Plin. $N H 4,116$ ) como el mismo nombre de la ciudad, Salacia, provendrían de la actuación de Sexto Pompeyo en la zona después de la batalla de Mun$d a$, donde situaría su taller, aprovechando que en esta localidad hubo anteriormente una ceca nativa en escritura sud-lusitana ${ }^{45}$ : ${ }^{*}$ Cantnipo (o $*$ Cauipon) (Correa 1982, 74. Faria 1988, 79), *Ketouibon (Untermann 1975, 343. Villaronga 1987, 166; 1994, 135. Estrada, 1992, 5. García-Bellido 1995, 396. Arévalo González 1998, 214) o *Beuipum (Faria 1993a, 193; 1995a, 143-145), y cuya abreviatura figuraría en el denario RRC 477.

La amonedación local hispánica de Salacia con cabeza de Neptuno en el anverso y letrero IMP. SAL. entre dos delfines (CNH 14-15. RPC 51A-B) se ha atribuido a este momento histórico, años 45/44 a.C., como emisión conmemorativa de la ciudad por este acontecimiento, sobre la base anterior más la conocida relación entre Sexto Pompeyo y la deidad ma-

${ }^{44}$ Grant $(1969,23)$, Tovar $(1976,214)$ y Faria (1995a, $147 ; 1995 \mathrm{~b}, 95-96)$, reconociendo este último que esta opinión está enfrentada con la del resto de los investigadores. Sobre esta localidad, cfr. Guerra (1995, 93-94).

45 Existen dificultades en cuanto a la transcripción de los símbolos de la escritura sud-lusitana en la que se redactó esta ceca. Sobre Salacia, cfr.: Faria, A. M. de, «Aínda sobre o nome pré-romano de Alcácer do Sal», Vipasca, 1, 1992, 39-48. rina Neptuno (Grant 1969, 23 n. 1; 95. Faria 1988, 79; 1993a, 193; 1995, 95-96; 1996, 117. RPC Suppl., p. 7. Ripollès 1998, 340). El apelativo Imperatoria (sobre el que descansa la atribución a esta ciudad de la acuñación pompeyana) quizás pudiera pertenecer a un periodo anterior a los hechos que aquí se relatan, posiblemente al de la conquista del territorio; las monedas locales del mismo nombre seguramente son asimismo de otro momento cronológico ${ }^{46}$.

También es difícil considerar a Salduie (la posterior Caesaraugusta) como ceca responsable de esta amonedación. Grant $(1969,23)$ se opuso en su momento a ello, aunque con el argumento de que ello no fue posible debido a que Sexto Pompeyo no ganó ciudades hasta su llegada a la Ulterior. Este extremo no es cierto, puesto que Sexto Pompeyo amonedó en Celsa, en el valle del Ebro, que invalida la solución esgrimida por este investigador. Desde luego, sería realmente extraño que en tan corto espacio de tiempo (hacia la mitad del año 45 a.C.) Sexto Pompeyo acuñase moneda bilingüe (Celsa) sin darse a conocer, y que a pocos kilómetros de distancia (Salduie) hiciese una acuñación de perfecto tipo romano con su nombre bien claro ${ }^{47}$.

De hecho, como ya se ha señalado anteriormente, estas atribuciones descansan en la aparición del letrero SAL en el denario de Sexto Pompeyo, palabra que puede tener otra restitución (como Salvus), sin tener nada que ver con el nombre de la ceca, aparte de que si bien se hallan estas letras en las emisiones RRC 477/1b, 477/2 y 477/3a, no se encuentran en las $n .^{\circ} 477 / 1$ a y $477 / 3$ b, aunque para Crawford ello no es óbice para pensar que el denario pudiera ser acuñado en diferentes cecas debido a este hecho (RRC, p. 94).

Las acciones principales de Sexto Pompeyo ${ }^{48}$ son, indiscutiblemente, realizadas en la parte meridional de la Península Ibérica, y es allí donde han de buscarse sus cecas, al menos de las monedas que se están aquí comentando. Esto en parte validaría las opiniones de situar la ceca de este denario en Salpensa o Salacia, pero ya se han ofrecido las dudas respecto al modo de llegar a esta solución. Por

46 Villaronga $(1994,135)$ no ofrece cronología alguna sobre estas monedas

${ }^{47}$ Los investigadores actuales que tratan esta importante ciudad del valle del Ebro no mencionan en absoluto la posibilidad de que en Salduie se realizase acuñación pompeyana alguna, cfr.: Fatás Cabeza, G. y Beltrán Lloris, M., Historia de Zaragoza, 1: Salduie, ciudad ibérica, Zaragoza, 1997.

${ }^{48}$ Cfr.: Gabba, E., «Aspetti della lotta in Spagna di Sesto Pompeo», en Legio VII, León, 1970, 131-155. Amela Valverde, L., «Sexto Pompeyo en la Península Ibérica», Historia $16,174,1990,68-72$. 
ello es más exacta la opinión de Sear (1998, 137 138), quien rechaza la interpretación de que SAL represente la ceca de la acuñación y piensa que la palabra debió de pertenecer a la leyenda del anverso, sin ofrecer una interpretación al respecto, aunque sin duda ésta debe de ir ligada a la palabra imperator.

A su vez, Grueber $(1910,371)$, sin seguir la tónica anterior, la atribuye a la ciudad de Carteia $^{49}$, en donde pudo establecer una ceca antes de derrotar a C. Asinio Polión, seguramente debido a una noticia de Cicerón quien dice que Sexto Pompeyo fue bien recibido en esta ciudad (Cic. Att. 15, 20, 3). Igualmente, es de destacar que Buttrey $(1960,85$ y 97), en relación a la ceca del presente denario, también ha pensado que si bien los que llevarían abreviatura SAL. serían acuñados en Salpensa, los que llevan la letra B (que también se halla en los de su hermano Cneo) serían acuñados en Baelo, aunque la presencia de esta letra en la moneda RRC 477/1a seguramente no es más que una supervivencia casual del mismo hecho que ocurre en las monedas de Cneo Pompeyo hijo (RRC, p. 94), es decir, un error por $\mathrm{F}$ (de filius), por lo que no hay que buscar en ésta la inicial de una ceca. Igualmente, Buttrey (1960, 88-90 y 96) considera que los denarios que no llevarían abreviatura de ceca (es decir, B. y SAL., que realmente no lo son) serían acuñados en Corduba, de lo que Zehnacker $(1965,286)$ concluye que el hecho de que este denario fuese acuñado en tres cecas (es decir, Salpensa, Baelo y Corduba) explicaría sus irregularidades en cuanto a estilo y factura.

En cuanto a los bronces, Grant (1969, 22 y 455) sitúa su ceca en Corduba. Por su parte, Beltrán Martínez (1947-1948, 218; 1950, 248) opina que el bronce de Sexto Pompeyo y M. Eppio se habría acuñado en Carthago Nova, debido a que según él se observa en el ara entre las dos caras de Jano una serpiente de Esculapio, lo que hace pensar en el símbolo local del culto de la Salud de la ciudad mencionada. De hecho, si bien en la emisión de RRC 478/1a se observa perfectamente el ara, no hay rastro de la serpiente citada por Beltrán Martínez; en la n. ${ }^{\circ} 478 / 1$ b ni tan siquiera está el altar. Igualmente, Crawford (RRC, p. 487) dice que el significado de este altar es desconocido, pero no tiene nada que ver con Esculapio. Por ello, hay que negar esta atribución (Amela 1990-1991, 191).

${ }^{49}$ Chaves $(1979,100)$ atribuye la abundante emisión local n. ${ }^{\circ} 22$ de esta ceca a magistrados propompeyanos del año 45 a.C., antes de la batalla de Munda.
Como se puede apreciar, el lugar de acuñación de estas piezas, el denario y los dos ases, es muy dudoso, sobre todo porque Sexto Pompeyo se trasladaba continuamente por toda la Península Ibérica, aunque se conoce bastante bien su actividad en la Bética, donde pasó más de la mitad de su estancia en Hispania. Por tanto, es lógico pensar que las cecas de estas monedas deben buscarse en la parte meridional peninsular (Gil Farrés 1966, 234), quizás en Corduba (donde Grant señalaba la emisión de los bronces) o en Carthago Nova, pero no existe ningún dato que pueda situar con alguna certeza el lugar donde se acuñaron estas emisiones (Amela 1990-1991, 191).

\section{BIBLIOGRAFÍA}

Alfaro Asins, C., 1996: «Avance de la ordenación de las monedas de Abderat/Abdera», Numisma, 237, 11-50.

AlföldI, A.,1956: «The Main Aspects of Political Propaganda of the Coinage of the Roman Republic», en Essays in Roman Coinage presented to Harold Mattingly, Oxford, 63-95.

Alteri, G., 1990: Tipologia delle monete della repubblica di Roma (con particolare referimento al denario), Città del Vaticano.

Amela ValVerde, L., 1990-1991: «La amonedación pompeyana en Hispania. Su utilización como medio propagandístico y como reflejo de la clientela de la gens Pompeia», Faventia, 12-13, 181-197.

Amela Valverde, L., 1994: «Las monedas de bronce acuñadas por Sexto Pompeyo en Hispania», GN, 113, 33-37.

Amela Valverde, L., 1998, «Las acuñaciones de Toleto y Clounioq.», GN, 118, 17-23.

Arévalo GonZÁlez, A., 1998: «Las acuñaciones ibéricas meridionales, turdetanas y de Salacia en la Hispania Ulterior», en Historia monetaria de Hispania antigua, Madrid, 194-232.

Arévalo González, A., 1999: La ciudad de Obulco: sus emisiones monetarias, Barcelona.

Arévalo González, A. y Marcos Alonso, C., 1997: «Dos reacuñaciones romano-republicanas sobre moneda hispánica», $\operatorname{MDAI}(M)$, 38, 67-74.

Arévalo, A. y CAmpo, M., 1998: «Las emisiones romanas y sus imitaciones en Hispania durante la República», en Historia monetaria de Hispania antigua, Madrid, 318-334.

Babelon, E., 1885: Description Historique et Chronologique des Monnaies de la République Romaine vulgairement appelées monnaies consulaires, Paris. 
Banti, A. y Simonetti, L., 1972: Corpus Nummorum Romanorum. Vol. I. Da Cneo Pompeo a Marco Antonio, Firenze.

Battenberg, Ch., 1980: Pompeius und Caesar: Persönlichkeit und Programm in ihrer Münzpropaganda, Diss. Marburg.

Belloni, G. G., 1960: Le Monete Romane dell'Età Repubblicana. Catalogo delle raccolte numismatiche, Milano.

Beltrán Martínez, A., 1947-1948: «El ara romana del Museo de Barcelona y su relación con el culto de la salud y Esculapio en Carthago Nova», Ampurias, 9-10, 213-220.

Beltrán Martínez, A., 1950: «Monedas de personajes pompeyanos en relación con Cartagena», en I Congreso Nacional de Arqueología $=V$ Congreso Arqueológico del Sureste Español, Cartagena, 246-258.

Beltrán Martínez, A., 1987: Introducción a la $\mathrm{Nu}$ mismática Universal, Madrid.

BERNAREGGI, E., 1963: Eventi e personaggi sul denari della Repubblica romana, Milano.

Blázquez Martínez, J. M., 1978: Historia económica de la Hispania romana, Madrid.

Broughton, T. R. S., 1952: The Magistrates of the Roman Republic. Volume II. 99 B.C.-3I B.C., Atlanta.

Burnett, A., 1987: Coinage in the Roman World, London.

Buttrey JR., Th. V., 1960: «The «Pietas» denarii of Sextus Pompey», NC, 10, 53-101.

CAMPo, M., 1973: «Los denarios romano-republicanos acuñados en Hispania», ANum, 3, 53-64.

Carson, R. A. G., 1978: Principal Coins of the Romans. Volume I. The Republic c. 290-31 B.C., London.

Chaves Tristán, F., 1979: Las monedas HispanoRomanas de Carteia, Barcelona.

Chaves Tristán, F., 1980-1981: «Los dos momentos de amonedación en la Corduba romana», $C o A$, $10,3-11$.

Chaves Tristán, F., 1991-1993: «Consideraciones sobre los tesorillos de monedas de bronce en Hispania. República e inicios del Imperio Romano. II», ANum 21-23, 267-284.

Chaves Tristán, F., 1993: «Hallazgo de un conjunto monetal a orillas del Guadalete (Cádiz)», en Stvdia Palaeohispanica et indogermánica J. Vntermann ab amicis hispanicis oblata, Barcelona, 117-129.

Chaves Tristán, F., 1996: Los Tesoros en el Sur de Hispania. Conjuntos de denarios y objetos de plata durante los siglos II y I a.C., Sevilla.

Chaves Tristán, F., 1998: «Amonedación de las ce- cas latinas de la Hispania Ulterior», en Historia monetaria de Hispania antigua, Madrid, 233317.

Chaves Tristán, F., 1999: «El papel de los «itálicos» en la amonedación hispana», Gerión, 17, 295-315.

Collantes Pérez-Ardá, E., 1987-1989: «Conjeturas sobre metrología ibérica», Numisma, 204-221, 29-107.

Combes, R., 1966: Imperator. Recherches sur l'emploi et la signification du titre d'Imperator dans la Rome républicaine, Paris.

Correa, J. A. (1982): «Singularidad del letrero indígena de las monedas de Salacia (a. 103)», $\mathrm{Nu}$ misma, 177-179, 69-74.

CRAwford, M. H., 1985: Coinage and Money under the Roman Republic, Berkeley.

Domergue, C., 1987: Catalogue des mines et des fonderies antiques de la Péninsule Ibérique, Madrid.

Domergue, C., 1990: Les mines de la Péninsule Ibérique dans l'antiquité romaine, Rome.

Estrada Aguilar, J. M. 1992: «Moneda de Ketovion», $G N, 104,5-6$.

Evans, J. D. R., 1987: «The Sicilian Coinage of Sextus Pompeius (Crawford 511)», ANSMunN, 32, 97-157.

FARIA, A. M. DE, 1988: «A numária de *Cantnipo», Conimbriga, 28, 71-99.

FARIA, A. M. DE, 1993a: «Moedas da época romana cunhadas no actual territorio português», en História de Portugal. Dos tempos pré-históricos aos nossos dias. Volume II. O mundo luso-romano. A Idade de Ferro e a ocupaçâo romana (Amadora), 192-196.

FARIA, A. M. DE, 1993b: [Sobre] A. Burnett, M. Amandry, P. P. Ripollès, Roman Provincial Coinage. Vol. I: From the death of Caesar to the death of Vitellius (44 BC-AD 69), 2 Parts, London-Paris, British Museum Press-Bibliothèque Nationale, 1992, 812 p.+195 est.», Vipasca, 2, 140-146.

FARIA, A. M. DE, 1995a: «Moedas de època romana cunhadas em território actualmente portugués», en La moneda hispánica. Ciudad y Territorio. Actas del I Encuentro Peninsular de Numismática Antigua (EPNA), Madrid, 143-153.

FARIA, A. M. DE, 1995b: «Plínio-o-Velho e os estatutos des cidades privilegiadas hispano-romanas localizadas no actual território portugués», $V i$ pasca, 4, 89-99.

FARIA, A. M. DE, 1996: «Emissôes monetárias, Imperatoria Salacia e Caesaraugusta. Algumas questôes historiográficas», Vipasca, 5, 117-119. 
Ferreiro López, M., 1993: «Los legados de César en España», en II Congreso Penínsular de Història Antiga, Coimbra, 399-415.

García-Bellido, M. P., 1982: Las monedas de Castulo con escritura indígena. Historia numismática de una ciudad romana, Barcelona.

GarCíA-Bellido, M. P., 1995: «Moneda y territorio: la realidad y su imagen», $A E s p A, 68,131-147$.

GarcíA-Bellido, M. P., 1996: «Las monedas hispánicas de los campamentos del Lippe: ¿Legio Prima (antes Augusta) en Oberaden?», Boreas 19, 247-260.

GIL FARRÉs, O., 1966: La moneda hispánica en la edad antigua, Madrid.

GoMes, A., 1996²: Moedas portuguesas e do territorio português antes da fundaçâo da nacionalidade. Catálogo das moedas cunhadas para o continente e ilhas adjacentes, para os territórios do ultramar e grâo-mestres portugueses da Ordem de Malta, Lisboa.

Grant, M., 1969²: From Imperium to Auctoritas. A Historical Study of Aes Coinage in the Roman Empire 49 B.C.-A.D. 14, Cambridge.

Grueber, H. A., 1910: Coins of the Roman Republic in the British Museum. Vol. II. Coinages of Rome (continued), Roman Campania, Italy, The Social War, and the Provinces, London.

Guerra, A., 1995, Plínio-o-Velho e a Lusitânia, Lisboa.

Hadas, M., 1930: Sextus Pompey, New York.

Herrero Albiñana, C., 1994: Introducción a la $\mathrm{Nu}$ mismática Antigua (Grecia y Roma), Madrid.

Hersh, CH., 1980: «The coinage of Quintus Labienus Parthicus», RSN, 59, 41-49.

Knapp, R. C., 1982: «The Coinage of Corduba, Colonia Patricia», AIIN, 29, 183-202.

KNAPP, R. C., 1987: «Spain», en The Coinage of the Roman World in the Late Republic, Oxford, 1942.

Kos, P., 1986: The Monetary Circulation in the Southeastern Alpine Region ca. 300 BC - AD 1000, Ljubljana.

LA RoccA, E., 1987-1988: «Pompeo Magno novus Neptunus», BCAR, 92, 265-292.

Marcos Alonso, C., 1989: «Imitaciones de numerario romano-republicano de bronce en el Museo Arqueológico Nacional», en VII Congreso Nacional de Numismática Madrid, 441-452.

Marcos Alonso, C., 1996: «Aportación a la circulación de las imitaciones de divisores romano-republicanos en la Península Ibérica», Numisma, 237, 199-223.

MARot, T., 1997: «Circulació i utilització de la moneda a l'Hispània de l'època d'August», en La moneda en temps d'August. Curs d'Història monetaria d'Hispània, Barcelona, 129-155.

MARTINI, R., 1988: Monetaziones bronzea romana tardo-repubblicana I. Divos Iulius di Octavianus, «assi» di Sextus Pompeius, emissioni dei prefetti di Antonius, Milano.

MARTINI, R. 1989: «Note metrologiche sulle emissioni bronzee di Sextus Pompeius», GN, 94-95, 23-29.

Michel, D., 1967: Alexander als Vorbild für Pompeius, Caesar und Marcus Antonius. Archäologische Untersuchungen, Bruxelles.

Millán, C., 1965: «Aspectos hispánicos de la familia Pompeia», en Congresso internazionale di Numismática, II. Atti 1961, Roma, 293-298.

Mora Serrano, B. (1989): «Sobre algunas reacuñaciones del taller de Acinipo», en VII Congreso Nacional de Numismática (Madrid), 213-223.

Morawiecki, L., 1983: Political Propaganda in the Coinage of the Late Roman Republic (44-43 B.C.), Wroclaw.

PÉrez, Ch., 1989: La monnaie de Rome à la fin de la République. Un discours en images, Paris.

Ripollès Alegre, P. P., 1995: «Una aproximación a las reacuñaciones en la Península Ibérica durante la Antigüedad», en La moneda hispánica. Ciudad y Territorio. Actas del I Encuentro Peninsular de Numismática Antigua (EPNA), Madrid, 289-296.

RiPOLlÈs Alegre, P. P., 1998: «Las acuñaciones cívicas romanas de la Península Ibérica (44 a.C.54 d.C.)», en Historia monetaria de Hispania antigua, Madrid, 335-395.

RPC = Burnett, A., Amandry, M. y Ripollès, P. P., 1992: Roman Provincial Coinage. Volume I. From the death of Caesar to the death of Vitellius (44 B.C.-A.D. 69). Part I: Introduction and Catalogue, London.

RPC Suppl. = Burnett, A., Amandry, M. y Ripollès, P.P., 1998: Roman Provincial Coinage. Volume I. From the death of Caesar to the death of Vitellius (44 B.C.-A.D. 69). Part I: Introduction and Catalogue. Supplement, I, London.

RRC = Crawford, M. H., 1974: Roman Republic Coinage, 2 vols., Cambridge.

Sáez Balaño, J. A. y Blanco Villero, J. M., 1996: Las monedas de la Bética romana. Vol. I. Conventus Gaditanus, San Fernando.

Seaby, H. A., 1967²: Roman Silver Coins Vol. I. The Republic to Augustus, London.

SEAR, R. S., 1998: The History and Coinage of Roman Imperators, 49-27 BC, London.

Sydenhaim, E. A., 1952: The Coinage of the Roman Republic, London. 
Syme, R., 1958: «Imperator Caesar: A Study in Nomenclature», Historia, 7, 172-188.

Tovar, A., 1976: Iberische Landeskunde. Die Völker und die Städte des antiken Hispanien. Band 2: Lusitanien, Baden-Baden.

Toynbee, J. M. C., 1978: Roman Historical Portraits, London.

TSIRKIN, JU. B., 1989: «The Veterans and the Romanization of Spain», Gerión, 7, 137-147.

UntermanN, J., 1975: Monumenta Linguarum Hispanicarum. Band I. Die Münzlegenden I. Text, Wiesbaden.

VillarongA, L., 1967: «Las monedas de Celse bilingües, posiblemente acuñadas por los pompeyanos», Caesaraugusta, 29-30, 133-142.

VILlARONGA, L., 1981: «Análisis estadístico de una muestra de monedas. Aplicación a las monedas de Corduba», QT, 10, 273-283.
VIllaronga, L., 1987: Numismática antigua de Hispania. Iniciación a su estudio, Barcelona.

Villaronga, L., 1994: Corpvs Nvmmorvm Hispaniae ante Avgvsti Aetate, Madrid.

Weinstock, S., 1971: Divus Iulius, Oxford.

Wiseman, T. P., 1971: New Men in the Roman Senate 139 B.C. 14 A.D., Oxford.

Woytek, B., 1995: «MAG PIVS IMP ITER. Die Datierung der sizilischen Münzpragung des Sextus Pompeius», $J N G, 45,79-94$.

ZEHNACKER, H., 1965: «L'iconographie pompèienne et les styles monétaires à la fin de la République Romaine», en Congresso internazionale di $\mathrm{Nu}$ mismática, II. Atti 1961, Roma, 283-292.

ZEHNACKER, H., 1978: «Systèmes monétaires et circulation des monnaies des Gracques à Auguste», en Le dernier siècle de la République Romaine et l'époque augustéene, Strasbourg, 3-12. 